\title{
Chapter 12 \\ Public Attitudes Toward Shared Custody: \\ The Czech Republic
}

\author{
Petr Fučík
}

\begin{abstract}
In the beginning of the existence of divorce as a social institution, parenthood was not as deeply problematized as the moral aspects of the partnership. In contrast, current public and scientific debates are most frequently involved in the questions of the impact of divorce on the children. Shared custody can be understood as a result of this cultural shift. The knowledge about public attitudes toward this topic and its social differentiation is limited. This study presents a unique source of data on shared custody attitudes from EVS (European Values Study) and CHPS (Czech Household Panel Survey) surveys conducted recently in the Czech Republic. The results show there is a substantive distinction between the attitudes of men and women and that the acceptance of shared custody is higher in younger age groups. No differences according to the social and economic status of respondents and their family backgrounds were found. Concerning the broader attitudinal contingency, we found no relationship between egalitarian gender attitudes and the acceptance of shared custody, but conservative attitudes toward divorce consequences increase the acceptance of shared custody.
\end{abstract}

Keywords Divorce $\cdot$ Shared custody $\cdot$ Joint physical custody $\cdot$ Attitudes $\cdot$ Czech Republic

\subsection{Introduction}

Although the research on shared custody is growing, little is known about public attitudes toward this issue. Few studies concern attitudes toward shared custody among people who have divorced (Smyth and Weston 2004; Fransson et al. 2016); some examine the attitudes of professionals (Majerčíková 2017), judges, or attorneys (Selleck et al. 1989; Kruk 2018; Braver and Lamb 2018), but no recent

\footnotetext{
P. Fučík ( $\square)$

Masaryk University, Brno, Czech Republic

e-mail: fucik@fss.muni.cz 
empirical data about the attitudes of the general public are available (cf. Coleman et al. 1999). This chapter examines public attitudes toward shared custody, using the opportunity to analyze data from two surveys conducted recently in the Czech Republic. The relevance of this topic is based on sociological arguments. As a relatively new phenomenon, shared custody lacks socially institutionalized forms and routine patterns of social action. The roles of social actors, model situations, key points, and even linguistic expressions are not fixed. In such a situation, an important role is played by transaction costs (Cherlin 1978, 2004), based on the level of societal acceptance of given forms of social action. In the early stages of institutionalization, it is important to know how thorny the paths are that are to be walked by the people practicing any form of shared custody.

The review part of this chapter presents an overview of the sociological explanations for the emergence of post-divorce shared custody arrangements and briefly reviews the most frequently presented topics in the literature on shared custody. Specific features of the Czech post-socialist context are then outlined, and particular hypotheses are developed. The analytical part of this chapter is introduced by the data and method specification, and it offers descriptive and exploratory results, which are discussed in relation to theoretical expectations derived from knowledge about parents who elect to share post-divorce custody.

\subsection{Shared Custody ${ }^{1}$ : A New Phenomenon in Post-Divorce Child Custody Arrangements?}

In the beginning of the existence of divorce as a social institution, parenthood was not considered to be a problem as much as the sacred, moral, and economical aspects of the partnership itself were (Cunningham 2005; DiFonzo 2014). In contrast, the current public debate as well as the academic one is most frequently involved in questioning the impact of divorce on the children (Amato 2000, 2010; Härkönen et al. 2017). While in the past, the interests of the children were certainly not a decisive factor in divorce proceedings, current divorces are largely organized with the utmost respect for the child participants (Elkin 1987; Kruk 2018). The logic behind custody decisions has changed over the past century from a patriarchal model in which the father, as the head of the family, was automatically entitled to the children, to a model giving preference to the mother, based on the idea of the natural priority of maternal care (Cancian and Meyer 1998; Cancian et al. 2014). Currently, ideas about the rights of the child to both parents and the rights (and

\footnotetext{
${ }^{1}$ Throughout this text, we use the term shared custody to describe the custody arrangements in which after a break-up both parents share the physical custody of their child(ren). We do not define specifically its meaning, nor the ratio of the sharing, because we use this term in its phenomenological sense as an agenda of public discourse. Usually, a time division from $25 \%$ to $50 \%$ spent with one parent is used to define shared custody (cf. Steinbach 2018). We also use shared custody in the same meaning as joint physical custody.
} 
duties) of both parents to fulfill their parental roles are at the forefront (Alstott 2004; Emery 2016).

From a historical and theoretical perspective, we can identify several societal processes leading to the increasing social relevance of arguments in favor of shared custody arrangements. The rising divorce rates across almost all western societies during the second half of the last century has expanded the number of children whose custody arrangements are decided partially by the parents and children themselves and partially by courts or other parties. At the same time, gender roles changed profoundly, so the traditional split between the private sphere as feminine and the public sphere as masculine no longer exists in the same force (Cooke 2006; Kaufman 2000; Kalmijn and Poortman 2006; Goldin 2006). As a result, parenting is not the exclusive central point of women's lives nor the symbolic source of women's public identity. At the same time, gender role changes led to the phenomenon informally called "new fatherhood," (Wahlstrom 2010; Doucet and Lee 2014) which draws attention to the failure of the model of the distant father. "New fathers" try to establish new forms of fatherhood, rejecting the stereotypical forms of fathering connected almost exclusively to the role of the father as a provider or as the source of patriarchal authority in favor of different nurturing styles (Pasley et al. 2014). These parental practices can be interpreted as part of a broader cultural shift concerning the ongoing development of the societal definition of a desirable childhood (or parenthood). The initial stages of this trend are deeply rooted in history (as noted by Ariès 1962) and current practices are influenced by relatively recent impulses from Bowlby's (Bowlby 1988) attachment theory on the academic side and intensive parenting (cf. Shirani et al. 2012) on the popular side. Hand in hand with these cultural trends, postmodern western families have significantly lower numbers of descendants, who therefore receive highly specialized, sophisticated, and thoughtful attention (cf. Badinter 1981; Bartlett and Stack 1986; Arendell 2000).

In this context, it is to be expected that the practice of simply putting the vast majority of children into the sole custody of their mothers will fade as a part of the disappearing world of traditionally defined gender roles and conceptions of childhood. As the historical memory of society is always limited, there is a strong tendency in the Czech Republic to understand the sole custody arrangement as the norm. Adopting a broader historical perspective, it seems more accurate to interpret this arrangement rather as a relatively brief (and very interesting) interplay between the older patriarchal logic of the exclusive rights of the father and the more recent egalitarian logic of the irrevocable rights of the child to a relationship with both parents and vice versa (Kruk 2018; Braver and Lamb 2018).

\subsection{Research on Shared Custody}

Although the public discussion understands shared custody as a new phenomenon, a significant body of research has become available since its introduction in the later twentieth century, and recent studies have increasingly taken the form of 
meta-analysis (Bauserman 2012; Baude et al. 2016; Nielsen 2014, 2017, 2018a) or review studies (Steinbach 2018). The most common subjects of empirical studies are the determinants of the choice of shared custody (Fox and Kelly 1995; Wilcox et al. 1998; Fransson et al. 2016), its practice in various types of families (Birnbaum and Saini 2015), the legal and economic aspects of shared parenting, and the adaptation of adults and children to this arrangement (Bauserman 2002, 2012).

As in divorce research, the most frequent (and politically sensitive) topic of studies on shared custody is the assessment of its impact on children. This can also be understood as a subset of the broader body of research conducted on the impacts of divorce. ${ }^{2}$ A number of studies are devoted to the various aspects of the relationship between different post-divorce custody arrangements and the various outcomes for the children. Better outcomes for children raised in shared custody as compared to other post-divorce arrangements is confirmed repeatedly, and consensus on this issue reaches almost across scientific literature (Nielsen 2018a, b; Sanford and Votruba 2018). But questions remain about the causality of this relationship (Smyth et al. 2016). To what extent are these results due to families choosing shared custody? Logically, shared custody is often preferred in families more likely to be characterized by higher income (Bauserman 2002; Fehlberg et al. 2011; Cancian et al. 2014), lower levels of conflict between parents or between parents and children; families in which the divorce process was easier; and families with both parents involved in the child care (Juby et al. 2005) and motivated to cooperate even if there is a break up (Smyth 2004; Gunnoe and Braver 2001). These selective mechanisms serve as important justifications for advocates of sole custody arrangements to dismiss the findings of better outcomes for children commuting between two homes. Original empirical research as well as extensive metanalytical and review studies show systematically that even if we control for the level of parental conflict and other circumstances, shared custody still produces the least negative effects, compared to other post-divorce custody arrangements (Nielsen 2017, 2018a; Steinbach 2018).

\subsection{Public Attitudes Toward Shared Custody}

In sociological theory, the word attitudes refers to the normative aspects of social institutions. Compared to values, which are deeply rooted in personal moral beliefs and as such are more permanent orientation structures, attitudes stem from opinions on specific subjects and create subjective normative feelings about it (Smyth 2016). The relevance of attitudes is based on the concept of the transactional costs of social action (Lauer and Yodanis 2010). General public attitudes on shared custody form the environment for social actions, the transactional costs of which rise with the level of negative attitudes, rejection, or stigmatization of the given forms of the

\footnotetext{
${ }^{2}$ Some scholars provocatively re-frame the whole conventional research on the impact of divorce on children as research on the impact of sole custody arrangements (Nielsen 2018b).
} 
social action. Although post-divorce custody arrangements are the subject of heated public debates, there is no sociological research on its reflection in the general public.

Despite convincingly positive empirical results, the argument about shared custody continues in many western countries; debates are reopened, and the legislation itself, as well as the legal practice, is still being developed (Fehlberg et al. 2011; Kruk 2018). The general public debate and the scholarly production seem often to split into two different worlds with only a minor overlap. Although empirical research informs the professional discussions and decisions (hopefully), the public debate is driven by different sources.

In the post-Communist countries, the situation is even more problematic because of the permanence of legal practices favoring sole custody and the relatively slow dynamics of gender role changes (cf. Lišková 2018). Due to delays in opening the discussion and adopting new legal institutes, shared custody did not emerge as a real option until around 2000. Because of the limited time and (still) marginal quantity of families practicing shared custody, there is no research verifying whether the basic patterns found in empirical research hold in the specific context of the postCommunist society, with its specific history of gender role changes, ${ }^{3}$ high divorce rates, and traditional family values. Therefore, the public debate is polarized, driven by media images of divorced families with children shuttling between parents (Taševská 2017; Majerčíková 2017) and feelings of discrimination (Fafejta 2018). The empirical findings of research on shared custody are reported only selectively, used as arguments for various interest groups or activists.

In the Czech Republic, shared custody has been legally codified since 1998, even though the previous legislation did not explicitly exclude it. Over time, several case laws have emerged that tend to presume shared custody, but this option has not been legislatively embedded. In 2016 in the Czech Republic, looking at the court decisions concerning the divorce of parents, $77 \%$ of minors stayed with their mothers after divorce, $7 \%$ stayed with their fathers, and $16 \%$ were in shared custody ${ }^{4}(\mathrm{Czech}$ Statistical Office 2017). No reliable data about broken cohabitations is available.

Concerning the factors affecting attitudes toward shared custody, we formulate five hypotheses based on the following theoretical arguments. Shared custody disrupts the traditional gendered logic of role division, and its emergence is connected with the spread of gender role transformations through society. The increasing prevalence of shared custody is to the detriment of sole custody, which is mostly assigned to women. The same trend thus has very different connotations for men and women (Fox and Kelly 1995). The gender differences in attitudes emerge partly due to the clash of two parallel gender ideologies. On one side, there is a notion of intensive

\footnotetext{
${ }^{3}$ The divergence from the western dynamic of gender roles is partly caused by the persistence of the high level of participation in the labor force by women after WWII, connected with the state propositions of gender equality (for more see Lišková 2018).

${ }^{4}$ This proportion was reached quite recently. The first decade after introducing the new law, the percentage of decisions in favor of shared custody was lower than 5\%; after 2010, the proportion started to increase more rapidly.
} 
motherhood and an (almost exclusive) connection of women with parenthood through the arguments for breastfeeding, long maternal leave, and employer expectations. On the other side, current notions of fatherhood, influenced by egalitarian gender role attitudes, increase men's parental involvement, at least at the level of expectations. We expect that (1) attitudes will be strongly divided along the gender of the respondents.

The generational point of view is also important, because in most societies the turn toward shared custody is a very recent trend that considerably alters the generational experience of union dissolution. We can expect the cohort effects because of different gender socialization and different discourses of parenthood (particularly, the post-Communist transformation period is characterized by rapid changes in the institutional nature of family, marriage, and parenthood). The effect of the life path is also very likely to be an important factor in the construction of attitudes towards shared custody; therefore, we control the age effect for the partnership/divorce experience and parental experience. Formally, in the hypothesis (2) we expect that attitudes will be divided along the age divisions of the respondents.

Studies examining the choice of post-divorce custody arrangements report the selective mechanisms among which the effect of higher status is one of the most important (Bakker and Mulder 2013). In most of the societies where empirical evidence is available, the option of shared custody is chosen by the more educated and more affluent parents (Cancian et al. 2014). Nevertheless, little is known regarding whether these differences are caused by different preferences or by the fact that shared custody requires more resources. The testing of hypothesis (3), that the higher social status of the respondents will lead to a higher acceptance of shared custody, will help to understand whether different attitudes exist, or whether the choice is driven by economic reasons or different reasons.

The last two hypotheses are formulated on the basis of sociological arguments about general gender role development and the de-stigmatization of divorce. Gender roles are developing in a more egalitarian direction, which is consistent with the abandonment of the preference for sole custody models (Juby et al. 2005; Kalmijn and De Graaf 2000). Our hypothesis (4) is that egalitarian gender-role attitudes will lead to positive attitudes toward shared custody. Based on the notion of a broader divorce culture (Hackstaff 1999), which means a wider acceptance of divorce throughout societies, the final hypothesis (5) anticipates that the positive attitudes toward shared custody will be tied to open attitudes toward divorce.

\subsection{Methods and Data}

The basis for the analysis is the assessment of statements concerning respondents' attitudes toward the phenomenon of shared custody. Unlike other sources in which divorced (or divorcing) people were asked about their choice or preference, our data stem from a survey of the broader public on the opinion of which custody option is better, according to personal subjective feelings. This difference leads to varying 
interpretations of the results: we do not expect to predict the behavior of the affected population, but we are interested in determining what the results indicate about the structure of attitudes representing part of the cultural milieu of a given society.

We analyze the data from two different surveys conducted in the Czech Republic in 2016 and 2017 to compare and triangulate the results obtained by slightly different methodologies. Each survey offers a different wording of the question and different response options.

In the Czech Household Panel Survey (CHPS), ${ }^{5}$ the question about shared custody was part of a broader battery of questions focused on the divorce culture. ${ }^{6} \mathrm{We}$ also use the other three items to indicate attitudes toward divorce. The battery was introduced by the instruction:

We know that in each particular case, one should always consider the circumstances, but let's try to discuss your general opinions on marriage and divorce. To what extent do you agree with the following statements?

The following items were evaluated by respondents on a four-point Likert scale, ${ }^{7}$ measuring the level of agreement.

Children after divorce should be in shared custody rather than with just one of their parents.

Divorce leads to a more fulfilling life.

Divorce mostly causes irreparable injuries to the children.

If there are children in the family, parents should stay together.

The second source is the Czech country dataset from the European Values Survey (EVS) project, collected in 2017. The size of the sample is 1812 respondents, ages 18-97 years. The question concerning shared custody was used only in the Czech country-specific part of the questionnaire, and dichotomous answers were offered.

Some people say it is better for the child to stay with one of the parents after divorce; others are in favor of shared custody. Generally speaking, what is your opinion of these options?

Two answers were offered:

It seems to me that it is better if the child stays with one of the parents or

Shared custody seems better to me.

We used the set of characteristics of respondent (sex, age, partner status, educational and income level, presence of children in household, religiosity, and family background) and the measures of gender role attitudes and attitudes toward divorce

\footnotetext{
${ }^{5}$ The project started in 2015; here, we make use of the second wave, fielded in 2016. The sampling unit in this survey is the household. The sample of individual adults representing general public opinion: 4877 individuals ages $18-90$ provided a response for the above-mentioned question.

${ }^{6}$ The design of these indicators was inspired by Hackstaff's notion of divorce culture as a set of values, beliefs, and attitudes as a social reaction to high divorce risk. The divorce culture is contradictory to the marriage culture, in which marriage is taken for granted (Hackstaff 1999).

${ }^{7}$ The answering categories were strongly disagree; somewhat disagree; somewhat agree; and strongly agree.
} 
as the independent and control variables. These variables are described in detail in the descriptive part of the analysis.

The analysis starts with descriptive statistics (cross-tabulation and means comparison) showing the bivariate associations between the attitudes toward shared custody and the set of independent and control variables. We then proceed with binary logistic regression models searching for factors influencing the dichotomic outcome of positive vs. negative attitudes toward the shared custody. Models are built for the whole datasets and then for both sexes separately.

\subsection{Descriptive Results}

The overall results show that the proportion of respondents who evaluate shared custody as a better option is between $39 \%$ and $48 \%$ (see Table 12.1). If the question is measured on a Likert-type four-point scale, $47.8 \%$ of the responses are in favor of shared custody and $52.2 \%$ are against it. Slightly different wording and the need to choose between two options leads to a lower level of acceptance of shared custody, which, according to the EVS 2017 survey, reaches 39.3\%, as opposed to $60.7 \%$ in favor of the sole custody arrangement. ${ }^{8}$

However, this picture does not reveal the heterogeneity in the data. As we expected, the most substantial difference is between men and women. In both surveys, the difference is more than 20 percentage points; still, almost one third of women accept the idea of shared custody.

The attitude toward shared custody is also affected by the age of the respondents. About half of responses from the youngest age group (18-40) show positive attitudes (55\% in CHPS and $49 \%$ in EVS). The cross-sectional data do not make it possible to measure whether these trends are due to a life course effect or cohort effect, but based on knowledge about differences in other family attitudes, we expect that these trends are the result of the different socialization of different cohorts (cf. gender-role attitudes).

Although most studies (Poortman and van Gaalen 2017; Bauserman 2002; Fehlberg et al. 2011; Cancian et al. 2014) argue that shared custody preference goes hand in hand with higher social and economic status; this association does not seem to occur in relation to attitude. Neither educational level nor family income plays a role in the attitude toward shared custody. Both surveys show rather small differences; even controlling for the association in the subgroups defined by gender and age category, the influence of educational level and family income is not seen, with one exception: the men in the oldest age cohort, whose acceptance of shared custody rises with their educational level.

\footnotetext{
${ }^{8}$ Only the valid responses were used. Responses of "don't know/have no opinion" reached $8 \%$ in CHPS data and $18 \%$ in EVS (the difference is probably caused by the necessity to choose between two options in EVS data).
} 


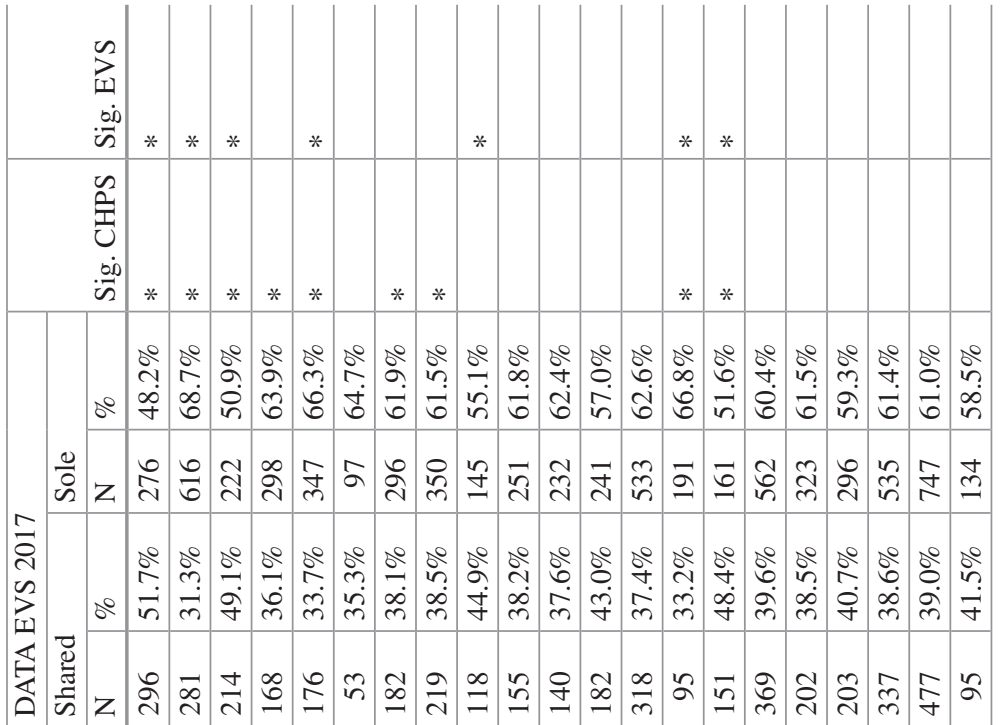

ஹீ

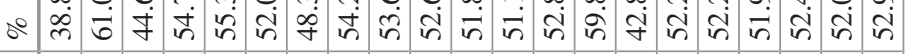

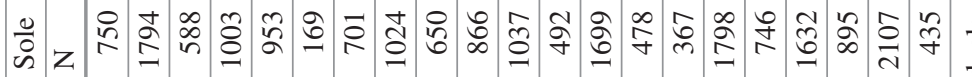

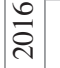

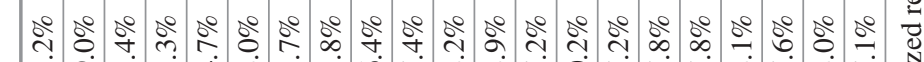

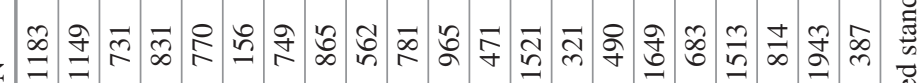

3 
Table 12.2 Mean values of the indicators of gender-role attitudes and divorce attitudes

\begin{tabular}{|c|c|c|c|c|c|}
\hline & \multicolumn{2}{|c|}{$\begin{array}{l}\text { DATA CHPS } \\
2016\end{array}$} & \multicolumn{2}{|c|}{$\begin{array}{l}\text { DATA EVS } \\
2017\end{array}$} \\
\hline & & Shared & Sole & Shared & Sole \\
\hline \multirow[t]{5}{*}{$\begin{array}{l}\text { Gender-role } \\
\text { attitudes** }\end{array}$} & $\begin{array}{l}\text { Man's job is to earn money; woman's job } \\
\text { is to look after home and family (CHPS, } \\
\text { EVS) }\end{array}$ & $3.10^{*}$ & $3.24^{*}$ & $2.55^{*}$ & $2.45^{\circ}$ \\
\hline & $\begin{array}{l}\text { A pre-school child is likely to suffer if his } \\
\text { or her mother work (CHPS, EVS) }\end{array}$ & $3.02^{*}$ & $3.22^{*}$ & 2.78 & 2.71 \\
\hline & $\begin{array}{l}\text { Both should contribute to the household } \\
\text { income (CHPS) (reversed) }\end{array}$ & 4.70 & 4.70 & - & - \\
\hline & $\begin{array}{l}\text { Family life suffers when woman has } \\
\text { fulltime job (EVS) }\end{array}$ & - & - & 2.64 & 2.59 \\
\hline & $\begin{array}{l}\text { A job is all right, but what most women } \\
\text { really want is a home and children (EVS) }\end{array}$ & - & - & 2.10 & 2.11 \\
\hline \multicolumn{2}{|c|}{$\begin{array}{l}\text { Gender index (CHPS: } 3 \text { items, 5-point scale; EVS: } 4 \text { items, } \\
\text { 4-point scale) }\end{array}$} & $3,61^{*}$ & $3.72^{*}$ & 2.52 & 2.47 \\
\hline \multirow[t]{3}{*}{$\begin{array}{l}\text { General divorce } \\
\text { attitudes }\end{array}$} & $\begin{array}{l}\text { Divorce leads to a more fulfilling life } \\
\text { (CHPS) }^{* * *}\end{array}$ & $2.81^{*}$ & $2.88^{*}$ & - & - \\
\hline & $\begin{array}{l}\text { Divorce mostly causes irreparable injuries } \\
\text { to the children (CHPS) }{ }^{* * *}\end{array}$ & $1.73^{*}$ & $1.93^{*}$ & - & - \\
\hline & $\begin{array}{l}\text { If there are children in the family, parents } \\
\text { should stay together (CHPS) }\end{array}$ & $3.63^{*}$ & $3.95^{*}$ & - & - \\
\hline
\end{tabular}

"Significance test Mann-Whittney sig. $<0,05$

${ }^{* *}$ Measured on 5-point scales in CHPS and 4-point scales on EVS; $1=$ strongly agree and $4 / 5=$ strongly disagree

${ }^{* * *}$ Measured on 4-point scales in CHPS; $1=$ strongly agree and $4=$ strongly disagree

${ }^{* * * * *}$ Measured on 5 -point scale in CHPS; $1=$ strongly agree and $5=$ strongly disagree

The influence of partnership experience could be partially attributed to respondent age (in both surveys, people who have never married have the most positive attitudes), but the difference between married and divorced people is interesting: people who have experienced divorce have slightly more reserved attitudes to shared custody.

No other family or respondent characteristic influences the level of acceptance of shared custody in Czech society: the responses are almost the same among those who live with children in the household and those who do not; there is no effect of religion, and even the experience of a single-parent family in childhood does not affect opinions about shared custody.

Inspired by the literature on the factors affecting the choice of shared custody, we focus on two sets of attitudes that could influence the acceptance of shared custody. We assume the approach to shared custody is a part of a broader set of attitudes concerning at least two important dimensions: the dimension of gender-role attitudes and the attitudes connected to the phenomenon of divorce itself. For the first dimension, we use items measuring gender-role attitudes associated in an additive index (gender-index) (see Table 12.2). ${ }^{9}$

\footnotetext{
${ }^{9}$ The index is constructed as a mean value of three or four items associated in the gender attitudes set of questions. Although there are more items available in the EVS and CHPS dataset, we use the
} 
To indicate the second dimension, we decided to use three indicators of "divorce culture": the belief that divorce leads to a more fulfilling life; the opinion that divorce causes irreparable injuries to the children; and the notion that if there are children in the family, parents should stay together. The intercorrelations of these items are too small to merge them into an additive index; hence, we use them separately.

\subsection{Exploring Factors Affecting Attitudes Toward Shared Custody}

To estimate the effects of the given factors, we used a model of binary logistic regression with the option of sole custody (0) or shared custody (1) as the dependent variable. ${ }^{10}$ As a set of independent variables, we used the above-mentioned indicators of individual and status characteristics (sex, age, education level, and household income of respondent). We also used control variables, mostly to control for the account of individual life path and family background (presence of children in household, family type, and family background). The last set of independent variables is the measure of gender-role attitudes and indicators of the attitudes toward divorce itself.

We estimated the models in three stages: (1) to compare the results of exactly the same model between two datasets (model $A$ ), then $(2)$ to use the full potential of explanatory variables available on each dataset (gender roles and divorce attitudes present in model B), and (3) to split between the subsets of men and women to determine whether the influence of given variables differed inside groups defined by sex (model $C) .{ }^{11}$

The overall image is very similar to the results of descriptive statistics, and different models constructed on different datasets provide similar results ${ }^{12}$ (see Table 12.3). The most important factors in the model are the respondent's sex and age. The sex of the respondent accounted for most of the explanatory power of the

\footnotetext{
questions that show satisfactory levels of internal consistency. Only valid responses were used; the "don't know/no opinion" category represents between $2 \%$ and $4 \%$ of responses.

${ }^{10}$ The institution of shared custody is in its beginning stages in the Czech Republic; therefore, we decided to use only two post-divorce custody arrangements. Other arrangements or variant models to 50/50 shared custody are almost invisible in the public debate.

${ }^{11}$ The last model is estimated only for CHPS data because the smaller EVS dataset does not provide any significant results.

${ }^{12}$ The most important discrepancy between EVS and CHPS data is the systematic offset in the overall level of acceptance of shared custody - as noted in the previous chapter, we assume this offset is the result of the different wordings of the questions used to measure the attitudes. Nonetheless, the patterns of gender difference, effect of age, limited influence of status variables, and no effect of gender-role attitudes identified in both datasets seem to be almost identical.
} 


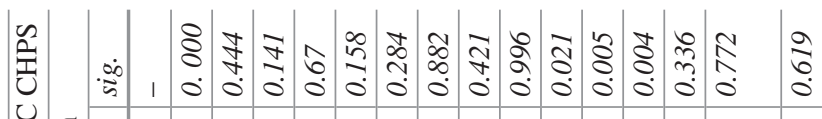

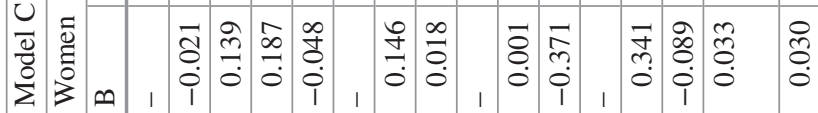

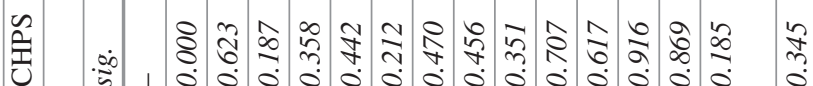

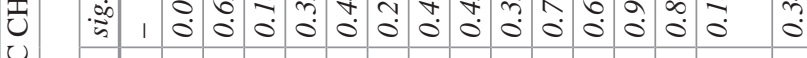

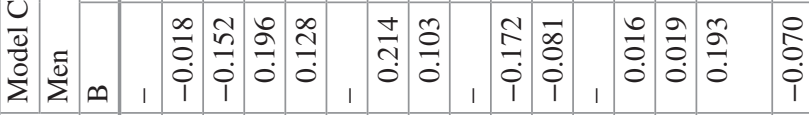

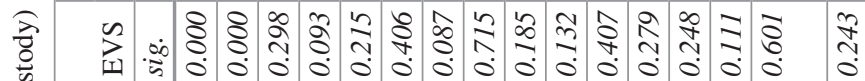

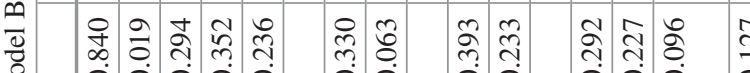

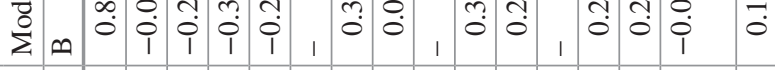

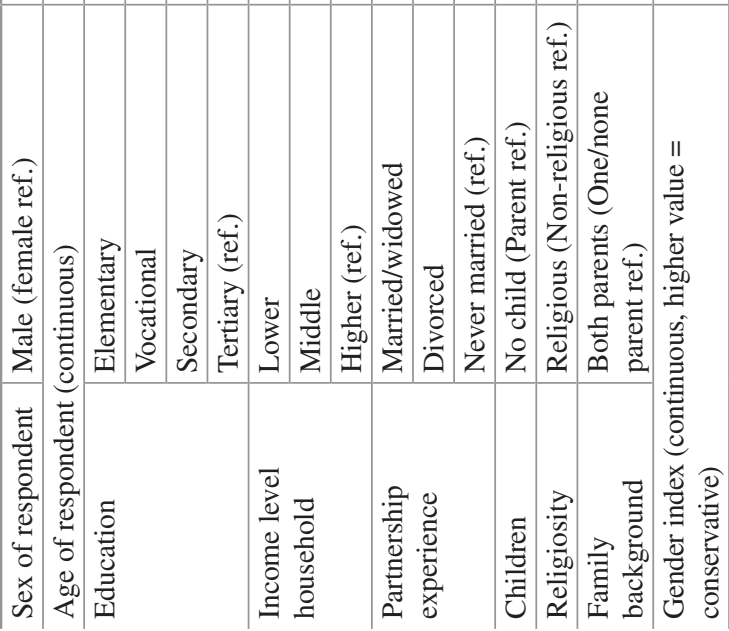




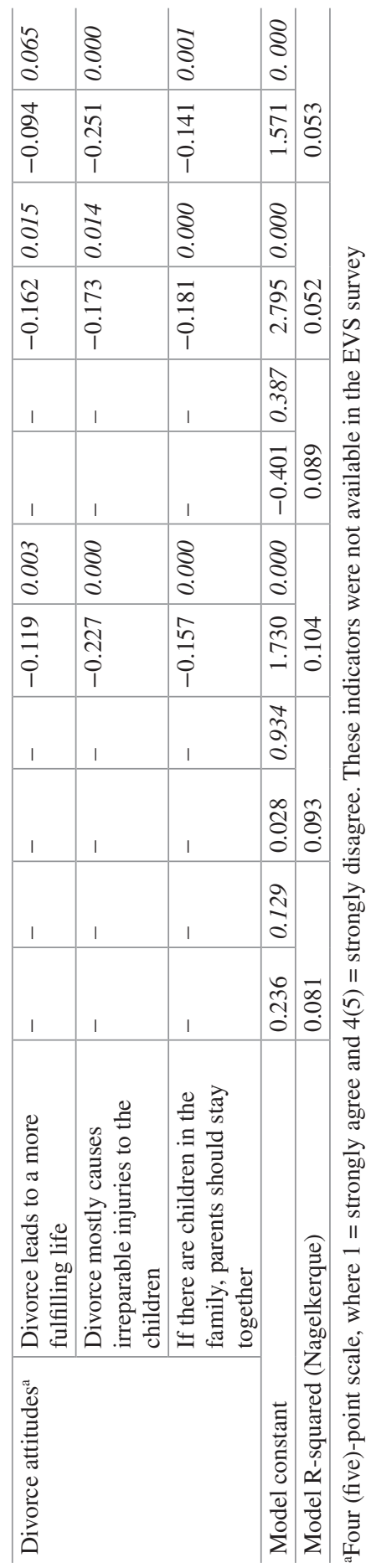


model, ${ }^{13}$ but also served as the control for the effect of other variables. Indicators of social status do not influence the acceptance of shared custody. Only the vocational level of education raises the acceptance of shared custody according to the CHPS survey, which means the effect of educational level is non-linear and contradictory to our hypothetical assumptions. Personal divorce experience as well as the presence of children in the household diminish the level of acceptance of shared custody. If the model for both sexes is split (see model C), the effect of life path is weaker for men and stronger for women. Particularly, women without children and without having experienced a divorce are more likely to hold positive attitude toward shared custody.

The lack of effect of gender-role attitudes is a bit surprising. Small and nonsignificant parameters for the gender index in both surveys show that the acceptance of shared custody is not connected to specific (particularly egalitarian) gender-role attitudes (see model $B$ ). The set of variables measuring the attitudes toward divorce and gender-role balance in the household is available only in the CHPS; therefore, from this point we will use only the CHPS dataset. A regression model shows a positive association with divorce attitudes, indicating that more positive attitudes toward shared custody are usually held by people who think that (1) divorce can lead to a more fulfilling life, (2) divorce causes mostly irreparable injuries to children, and (3) partners should stay together when there are children. The first statement sounds liberal, while the other two have traditional connotations - this seems to be in contradiction. A possible explanation could be that the first statement is oriented to the divorcees themselves, but the other two concern the impact on children.

\subsection{Discussion}

Within the research on post-divorce custody arrangements, very little is known about the general public attitudes, particularly attitudes toward the topic of shared custody. We consider this factor to be important especially in societies in which the institution of shared custody is in its beginning stages and the public discussion is still rather polarized, ambiguous, or confused. In the Czech society, with its high divorce rate, we found relatively open public attitudes toward shared custody, particularly among younger age groups and men, to be in sharp contrast with its low incidence in court decisions. In an effort to find the factors that shape individual attitudes, we tested five hypotheses, expecting effects of (1) sex and (2) age, (3) social status, (4) gender-role attitudes, and (5) divorce attitudes. We found support for the first two and last hypotheses, and no support for the third and fourth. It is not surprising that men and women differ in their attitudes; the ratio is about $60 / 40$ accepting shared custody. The gender division of the attitudes is the strongest pattern in the data. The numbers accepting shared custody are higher in the younger

\footnotetext{
${ }^{13}$ See the change of R-squared statistics between the models A, B, and C.
} 
age group and much lower in the older. These results are in line with the theoretical explanations based on the generational experience and feelings of novelty of shared custody model.

Although many studies show that higher-status families are more likely to choose shared custody arrangements, the situation seems to be different in expressed attitudes. Our results do not show any important effect of educational level, nor of family income. Therefore, we reject the third hypothesis. This should be further examined, particularly in groups with actual divorce experience, because the discrepancy between attitudes and choices could indicate structural barriers, rather than negative preferences causing different choices.

The effect of gender-role attitudes is also missing from the data, leading us to reject our third hypothesis. There are strong theoretical arguments for the existence of a link between the gender order of society and the emergence of shared custody (Wahlstrom 2010; Doucet and Lee 2014), but the nature of this association on the individual level may differ. The measurement of gender-role attitudes can be too focused on the work/family division and may not reflect other spheres of gender equality.

Testing the fifth hypothesis provides results suggesting that the acceptance of shared custody is connected to conservative views on divorce rather than to liberal ones. People's skepticism about the impact of divorce on children is probably what drives their attitudes toward shared custody, rather than egalitarian gender-role attitudes.

\subsection{Conclusion}

We obtained a general image that shows, despite a rather negative connotation of shared custody in the media and its relatively rare occurrence in child custody judgments, that this form of arrangement is not rejected by the Czech public. There is still, without doubt, a gender and generational imbalance, since the expansion of shared custody is at the expense of recent practices that tended to favor maternal custody.

Public attitudes toward shared custody are rarely studied; nevertheless, they constitute an important part of the post-divorce adaptation process. It is not only the preferences of the divorcees, but the overall social milieu that affect the extent to which the various forms of post-divorce parenting are stigmatized. It is a matter of the attitudes of relatives, friends, neighbors, professionals in custody, teachers, schoolmates, parents of schoolmates, etc. The dynamics of the attitudes are a key topic for future research. Our results show a negative age gradient of acceptance of shared custody, but the cross-sectional study design does not allow us to interpret whether this is a result of a changing generational experience or the effect of life paths and the attitudes will change with the experience of marriage or parenthood. Comparing more points in time will help to strengthen arguments for one or another explanation. 
The study of attitudes toward post-divorce custody can also reveal the extent of potential tension in the fragility and irreversibility of de-institutionalizing the commitments of marriage and parenthood. On the one hand, partnerships are increasingly fragile and the stigma of dissolution is weakening. On the other hand, the intergenerational ties represented by the rights and obligations of both parents to share custody are becoming a higher priority. Shared custody reflects a search for a compromise between these two contradictory trends of partnership individualization and parenthood commitment, trends which are deeply rooted in the development of post-modern societies. The most important message in this respect is that even in a society where the change of legal practice is rather slow, the acceptance of such a compromise reaches higher proportions than its actual prevalence in court decisions.

Acknowledgement This study was financially supported by the Czech Science Foundation (grant no. GB14-36154G), 'Dynamics of Change in Czech Society'.

This chapter benefited from the support of the Centre for Population, Family and Health $(\mathrm{CPFH})$ at the University of Antwerp and the Flemish Agency of Innovation and Entrepreneurship (Grant number: 140069), which enabled Open Access to this chapter.

\section{References}

Alstott, A. L. (2004). No exit: What parents owe their children and what society owes their parents. New York: Oxford University Press.

Amato, P. R. (2000). The consequences of divorce for adults and children. Journal of Marriage and the Family, 62, 1269-1287.

Amato, P. R. (2010). Research on divorce: Continuing trends and new developments. Journal of Marriage and Family, 72(3), 650-666.

Arendell, T. (2000). Conceiving and investigating motherhood: The decade's scholarship. Journal of Marriage and the Family, 62(4), 1192-1207.

Ariès, P. (1962). Centuries of childhood: A social history of family life. New York: Vintage Books.

Badinter, É. (1981). Mother love: Myth and reality. Motherhood in modern history. New York: Macmillan.

Bakker, W., \& Mulder, C. (2013). Characteristics of post-separation families in the Netherlands: Shared residence versus resident mother arrangements. GeoJournal, 78(5), 851-866.

Bartlett, K. T., \& Stack, C. B. (1986). Joint custody, feminism and the dependency dilemma. Berkeley Women's Law Journal, 9, 9-41.

Baude, A., Pearson, J., \& Drapeau, S. (2016). Child adjustment in joint physical custody versus sole custody: A meta-analytic review. Journal of Divorce \& Remarriage, 57, 338-360.

Bauserman, R. (2002). Child adjustment in joint-custody versus sole-custody arrangements: A meta-analytic review. Journal of Family Psychology, 16(1), 91-102.

Bauserman, R. (2012). A meta-analysis of parental satisfaction, adjustment, and conflict in joint custody and sole custody following divorce. Journal of Divorce \& Remarriage, 53(6), 464-488.

Birnbaum, R., \& Saini, M. (2015). A qualitative synthesis of children's experiences of shared care post divorce. International Journal of Children's Rights, 23, 109-132.

Bowlby, J. (1988). A secure base: Parent-child attachment and healthy human development. New York: Basic Books.

Braver, S. L., \& Lamb, M. E. (2018). Shared parenting after parental separation: The views of 12 experts. Journal of Divorce and Remarriage, 59(5), 372-387.

Cancian, M., \& Meyer, D. R. (1998). Who gets custody? Demography, 35, 147-157. 
Cancian, M., Meyer, D. R., Brown, P. R., \& Cook, S. T. (2014). Who gets custody now? Dramatic changes in children's living arrangements after divorce. Demography, 51, 1381-1396.

Cherlin, A. (1978). Remarriage as an incomplete institution. American Journal of Sociology, 84(3), 634-650.

Cherlin, A. J. (2004). The deinstitutionalization of American marriage. Journal of Marriage and Family, 66(4), 848-861.

Coleman, M., Ganong, L. H., Killian, T., \& McDaniel, A. K. (1999). Child support obligations. Journal of Family Issues, 20(1), 46-68.

Cooke, L. (2006). "Doing" gender in context: Household bargaining and risk of divorce in Germany and the United States. American Journal of Sociology, 112(2), 442-472.

Cunningham, H. (2005). Children and childhood in western society since 1500 (2nd ed.). Harlow/ New York: Pearson Longman.

Czech Statistical Office. (2017). Focus on women and men 2016. Praha: Czech Statistical Office.

DiFonzo, J. H. (2014). From the rule of one to shared parenting: Custody presumptions in law and policy: From the rule of one to shared parenting. Family Court Review, 52(2), 213-239.

Doucet, A., \& Lee, R. (2014). Fathering, feminism(s), gender, and sexualities: Connections, tensions, and new pathways. Journal of Family Theory \& Review, 6(4), 355-373.

Elkin, M. (1987). Joint custody: Affirming that parents and families are forever. Social Work, $32(1), 18-24$.

Emery, R. (2016). Two homes, one childhood: A parenting plan to last a lifetime. New York: Avery.

Fafejta, M. (2018). The fathers' rights movement as a subaltern Counterpublic. Sociológia, 50(3), $225-245$.

Fehlberg, B., Smyth, B., Maclean, M., \& Roberts, C. (2011). Legislating for shared time parenting after separation: A research review. International Journal of Law, Policy and the Family, 25(3), 318-337.

Fox, G. L., \& Kelly, R. F. (1995). Determinants of child custody arrangements at divorce. Journal of Marriage and Family., 57(3), 693-708.

Fransson, E., Sarkadi, A., Hjern, A., \& Bergström, M. (2016). Why should they live more with one of us when they are children to us both? Parents' motives for practicing equal joint physical custody for children aged 0-4. Children and Youth Services Review, 66, 154-160.

Goldin, C. (2006). The quiet revolution that transformed Women's employment, education, and family. The American Economic Review, 96(2), 1-21.

Gunnoe, M. L., \& Braver, S. L. (2001). The effects of joint legal custody on mothers, fathers, and children controlling for factors that predispose a sole maternal versus joint legal award. Law and Human Behavior, 25(1), 25-43.

Hackstaff, K. B. (1999). Marriage in a culture of divorce. Philadelphia: Temple University Press.

Härkönen, J., Bernardi, F., \& Boertien, D. (2017). Family dynamics and child outcomes: An overview of research and open questions. European Journal of Population, 33, 163.

Juby, H., Le Bourdais, C., \& Marcil-Gratton, N. (2005). Sharing roles, sharing custody? Couples' characteristics and children's living arrangements at separation. Journal of Marriage and the Family, 67(1), 157-172.

Kalmijn, M., \& Poortman, A. (2006). His or her divorce? The gendered nature of divorce and its determinants. European Sociological Review, 22(2), 201-214.

Kaufman, G. (2000). Do gender role attitudes matter?: Family formation and dissolution among traditional and egalitarian men and women. Journal of Family Issues, 21(1), 128-144.

Kruk, E. (2018). Arguments against a presumption of shared physical custody in family law. Journal of Divorce \& Remarriage, 59, 5,388-5,400.

Lauer, S., \& Yodanis, C. (2010). The deinstitutionalization of marriage revisited: A new institutional approach to marriage. Journal of Family Theory \& Review, 2(1), 58-72.

Lišková, K. (2018). Sexual liberation, socialist style: Communist Czechoslovakia and the science of desire, 1945-1989. New York: Cambridge University Press.

Majerčíková, J. (2017). Joint child custody as a new kindergarten teachers' experience. Acta Technologica Dubnicae, 7(3), 99-110.

Nielsen, L. (2014). Shared physical custody: Summary of 40 studies on outcomes for children. Journal of Divorce \& Remarriage, 55, 613-635. 
Nielsen, L. (2017). Re-examining the research on parental conflict, coparenting and custody arrangements. Psychology, Public Policy and Law, 23, 211-231.

Nielsen, L. (2018a). Joint versus sole physical custody: Children's outcomes independent of parent-child relationships, income, and conflict in 60 studies. Journal of Divorce \& Remarriage, 59(4), 247-281.

Nielsen, L. (2018b). Preface to the special issue: Shared physical custody: Recent research, advances, and applications. Journal of Divorce \& Remarriage, 59(4), 237-246.

Pasley, K., Petren, R. E., \& Fish, J. N. (2014). Use of identity theory to inform fathering scholarship. Journal of Family Theory \& Review, 6(4), 298-318.

Poortman, A.-R., \& van Gaalen, R. (2017). Shared residence after separation: A review and new findings from the Netherlands: Shared residence in the Netherlands. Family Court Review, 55(4), 531-544.

Sanford, L. B., \& Votruba, A. M. (2018). Does joint physical custody "cause" children's better outcomes? Journal of Divorce \& Remarriage, 59(5), 452-468.

Selleck, L. R., Draughn, P., Waddell, F., \& Buco, S. M. (1989). Attitudes of attorneys and judges toward joint custody and its litigation. Journal of Divorce, 12(4), 103-116.

Shirani, F., Henwood, K., \& Coltart, C. (2012). Meeting the challenges of intensive parenting culture: Gender, risk management and the moral parent. Sociology, 46(1), 25-40.

Smyth, B. (2004). Parent-child contact schedules after divorce. Family Matters, 69, 32-43.

Smyth, B., McIntosh, J., Emery, R., \& Howarth, S. (2016). Shared time parenting: Evaluating the evidence of risks and benefits for children. In L. Drozd, M. Saini, \& J. Olesen (Eds.), Parenting plan evaluations: Applied research for the family court (pp. 118-170). New York: Oxford University Press.

Smyth, B., \& Weston, R. (2004). The attitudes of separated mothers and fathers to 50/50 shared care. Family Matters, 67, 8-15.

Smyth, L. (2016). The disorganized family: Institutions, practices and normativity: The disorganized family. The British Journal of Sociology, 67(4), 678-696.

Steinbach, A. (2018). Children's and parents' Well-being in joint physical custody: A literature review. Family Process. (EARLY VIEW).

Taševská, I. (2017). Mediální obraz stř́ídavé péče./Media image of shared custody. Czech \& Slovak Social Work/Sociální Práce/Sociálna Práca, 17(2), 58-70.

Wahlstrom, H. (2010). New fathers? Contemporary American stories of masculinity, domesticity and kinship: Contemporary American stories of masculinity, domesticity and kinship. Newcastle upon Tyne: Cambridge Scholars Publishing.

Wilcox, K., Wolchik, S., \& Braver, S. (1998). Predictors of maternal preference for joint or sole legal custody. Family Relations, 47(1), 93-101.

Open Access This chapter is licensed under the terms of the Creative Commons Attribution 4.0 International License (http://creativecommons.org/licenses/by/4.0/), which permits use, sharing, adaptation, distribution and reproduction in any medium or format, as long as you give appropriate credit to the original author(s) and the source, provide a link to the Creative Commons license and indicate if changes were made.

The images or other third party material in this chapter are included in the chapter's Creative Commons license, unless indicated otherwise in a credit line to the material. If material is not included in the chapter's Creative Commons license and your intended use is not permitted by statutory regulation or exceeds the permitted use, you will need to obtain permission directly from the copyright holder.

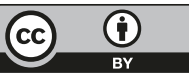

